\title{
A Goal Programming Model For Facility Location Planning
}

\author{
Albina Basholli, MSc \\ Polytechnic University of Tirana, Albania \\ Vasillaq Kedhi, Prof. Dr \\ University of Tirana, Albania \\ Alisa Cangonji, $\mathrm{MSc}$
}

Ghent University, Belgium

\begin{abstract}
The aim of this paper is to apply Goal Programming in facility location. The feasibility project of a project idea on building an economic object is a defining moment in the decision making of the party that is investing on a certain project. Generally, the feasibility is done based on the global data extracted by the practical experience of building and functioning of similar existing object. However, it is understandable that the accuracy of the feasibility results is increased when different points of view are used in combination with exact methods of calculation. In this aspect, it is important to predict the income from the use of the object's capacities. This leads to an intermediary problem which consists in predicting the most result oriented use of the object's capacities. If the use of these capacities can be mathematically modeled through optimization models, then the basis of the data for evaluating the feasibility of the object becomes clearer. In this study was considered the possibility of using a mathematical model for the basin used by a yacht harbor. As a result, it is shown that the optimal use of a basin by a yacht harbor can be modeled as an objective function problem, which according to previously known methods can turn into a mathematical programming problem.
\end{abstract}

Keywords: Facility location, goal programming, optimization

\section{Introduction}

Since tourism in Albania is a very important sector in the country's economy, the central administration and the local ones are re-evaluating our specific resources and creating the legal opportunities for using them through the drafting and approval of master plans in a local or national level. This 
sector of the economy is of special interest to different businessman and investors. In these circumstances the touristic capacities are vastly growing. Besides the existing structures, there are new state and private projects working on increasing the touristic capacities for the traditional activities or new ones. In these relatively rapid developments, it is noticeable that the importance of the projections and constructions of yacht harbors is increasing. Considering the size, structure and equipment that these harbors have, their cost could reach up to millions of Euros. In the time we are living in, when our experiences in building such touristic structures are not as developed, it is important that each aspect of the construction of these harbors is well studied, especially the technical, environmental and financial aspects. Another reason is the lack of the legal-administrative aspect of their functioning, which has allowed this touristic activity to remain not fully explored, although there is some public interest in their development. These reasons make the feasibility study of this project a very delicate situation which needs to be carefully treated by economists and technical planners.

\section{Problem statement.}

After defining the physical dimensions and the necessary structures of such a project, its cost can be calculated based on the volume of works to be done and the prices of materials and equipment. This cost must be compared to the predicted income from the harbor. But, based on what factors must this income be calculated? This is the crucial topic that is treated in this study, where as an alternative is proposed the use of mathematical models as shown below.

It is clear that the income coming from such a touristic harbor is connected not only to marketing aspects, but also to the way that boats are organized in its basin. Different ways of organizing the yachts in the harbor are characterized by their structure and size, and from different levels of income. Practically, the organizational system of yachts and motorboats is based on experience and individual assumptions. Obviously, if one must find an optimal use for the basin of the harbor, then the use of mathematical models would lead to more exact assumptions of the income. In this line of thinking we assume that harbor projects, besides their structural aspect, should be accompanied with the optimal planning of the basin. With such a basis, the feasibility study would be much more reasoned.

The international experience in constructing and rationally using touristic harbors has led to the advanced idea of using the basin not only along the coast line but in its inner part as well. This idea is technically realized with floating dock (jetties) along which are put the supply lines for electricity, technological water and fuel for the needs of the yachts. Normally, the form of the basin depends on the terrain where the harbor is 
constructed. But, having in mind how basins are formed by advancing in the sea and digging towards the ground, we take a triangular shape of the basin as a basis (fig. 1). However, the method we will explore here can be adapted to non rectangular shapes of the basin.

In this context we will name the touristic motorboats and sailing yachts that will be located in the touristic harbors with the common name of "boats". For their docking we will use the term "connection". The part of the water basin where a boat is connected to the other structures and furnishing will be named "boat-location".

Renting a boat location in the harbor can be short term (a few days) or long term (some decades). Since in the biggest part of the year the boat remains connected to a chosen harbor from its owner, the owner probably would prefer to have its own boat location for a longer time period. In the model that we will construct we will consider this way of using the harbor, which will generate profit for each boat location.

Obviously boats have different lengths, starting from $7 \mathrm{~m}$ up to $30 \mathrm{~m}$. There are also very luxurious yachts longer than $30 \mathrm{~m}$, which reside in harbors that fulfill the yacht's and owners specific requirements. Based on the managerial practices of harbors, the long term rent for a boat location, which normally depends on its length, is classified as below:

\begin{tabular}{|c|c|c|}
\hline Class & Its lengths & Rent euro/boat \\
$K_{i}$ & $g_{i}$ & $c_{i}$ \\
\hline $\mathrm{K}_{1}$ & up to $\mathrm{h}_{1}=8 \mathrm{~m}$ & $\mathrm{c}_{1}$ \\
\hline $\mathrm{K}_{2}$ & from $\mathrm{h}_{1}=8 \mathrm{~m}$ up to $\mathrm{h}_{2}=12 \mathrm{~m}$ & $\mathrm{c}_{3}$ \\
\hline $\mathrm{K}_{3}$ & from $\mathrm{h}_{2}=12 \mathrm{~m}$ up to $\mathrm{h}_{3}=15 \mathrm{~m}$ & $\mathrm{c}_{4}$ \\
\hline $\mathrm{K}_{4}$ & from $\mathrm{h}_{3}=15 \mathrm{~m}$ up to $\mathrm{h}_{4}=20 \mathrm{~m}$ & $\mathrm{c}_{5}$ \\
\hline $\mathrm{K}_{5}$ & from $\mathrm{h}_{4}=20 \mathrm{~m}$ up to $\mathrm{h}_{5}=25 \mathrm{~m}$ & $\mathrm{c}_{6}$ \\
\hline $\mathrm{K}_{6}$ & from $\mathrm{h}_{5}=25 \mathrm{~m}$ up to $\mathrm{h}_{6}=30 \mathrm{~m}$ & \\
\hline
\end{tabular}

The width of the boats is correlated to their length. For each of the groups $K_{i}, i=1, \ldots, 6$, the widths are known and reach known limits that we will appoint as $g_{i}, i=1, \ldots, 6$. The floating dock, in the configuration presented in figure 1, are parallel to each other and divided by an entrance canal in two groups. The length of the canal must be approximately $25 \mathrm{~m}$, which is enough for the boats to move freely. If the width of the water basin is small, then there can only be one group of floating dock and the entrance canal in this case will be from the side. The connection of the boats can be done through the two sides of the floating dock. Each yetty side is predicted large enough for certain types of boats (eventually, they can be connected to smaller boats).

The length $\mathrm{H}_{\mathrm{ij}}$ (or $\mathrm{H}_{\mathrm{k}}$ if we only take one indicator into account) between the two floating dock is calculated as the sum of the boat lengths of both classes $\mathrm{K}_{\mathrm{i}}, \mathrm{K}_{\mathrm{j}}$ plus 1.5 times the length of the biggest boat. This water 
streak is large enough to allow the boat to approach its location and perform what is needed. Afterwards, to the above mentioned sum is added another $2 \mathrm{~m}$, resulting in this formula:

$$
\mathrm{H}_{\mathrm{k}}=\mathrm{H}_{\mathrm{ij}}=\mathrm{h}_{\mathrm{i}}+\mathrm{h}_{\mathrm{j}}+1.5 \max \left\{\mathrm{h}_{\mathrm{i}}, \mathrm{h}_{\mathrm{j}}\right\}+2 .
$$

We will name this length the length of the water segment which serves to two classes $K_{i}, K_{j} i, j=1, \ldots, 6$. It is noticeable that the number of water segments is equal to the number of floating dock.

The length of the floating dock (fig. 1) is:

$$
\mathrm{d}=\frac{1}{2}(b-25) \text { meters }
$$

We assign $n_{i}$ the number of boats belonging to the classes $K_{i}$, $\mathrm{i}=1, \ldots, 6$ which can be connected through a floating dock. This number is:

$$
\mathrm{n}_{\mathrm{i}}=\left[\frac{d}{g_{i}}\right]^{C_{6}^{2}+6=21}
$$

Water segments can be created for every combination of the boat classes $\mathrm{K}_{\mathrm{i}}, \mathrm{K}_{\mathrm{j}} \quad \mathrm{i}=1, \ldots, 6$ and $\mathrm{j}=1, \ldots, 6$. In our case their total number is

$$
\mathrm{n}=\mathrm{C}_{6}^{2}+6=21
$$

The types of water segments that correspond to the different combinations $\left(\mathrm{K}_{\mathrm{i}}, \mathrm{K}_{\mathrm{j}}\right)$ of the boat classes will be assigned as $\mathrm{T}_{\mathrm{k}}, \mathrm{k}=1, \ldots, 21$ counted according to this row of combinations: $\left(\mathrm{K}_{1}, \mathrm{~K}_{1}\right),\left(\mathrm{K}_{1}, \mathrm{~K}_{2}\right), \ldots,\left(\mathrm{K}_{1}, \mathrm{~K}_{6}\right)$, $\left(\mathrm{K}_{2}, \mathrm{~K}_{2}\right), \ldots,\left(\mathrm{K}_{2}, \mathrm{~K}_{6}\right), \ldots,\left(\mathrm{K}_{6}, \mathrm{~K}_{6}\right)$. The respective lengths of these segments will be noted as $h\left(T_{k}\right), k=1, \ldots, 21$. The amounts of the boats belonging to each class which can be connected to a water segment $\mathrm{H}_{\mathrm{k}}$, as calculated in equation (2), are:

$$
\mathrm{n}_{\mathrm{i}}(\mathrm{k})=\left[\frac{\mathrm{d}}{\mathrm{g}_{\mathrm{i}}}\right] \text { and } \mathrm{n}_{\mathrm{j}}(\mathrm{k})=\left[\frac{\mathrm{d}}{\mathrm{g}_{\mathrm{j}}}\right] \text {. }
$$

These amounts are shown in table 1. In continuance of each row from that table are written the numbers $c_{1}, \ldots, c_{6}$ which represent the prices for a boat location of each class $\mathrm{K}_{\mathrm{i}}, \mathrm{i}=1, \ldots, 6$ that are considered as components of the price vectors $c \in R^{6}$.

A layout of water segments in the harbor is defined by the numbers $\mathrm{x}_{\mathrm{k}}$ of the water segments of each type $\mathrm{T}_{\mathrm{k}}, \mathrm{k}=1, \ldots, 21$ which are predicted to be established in the harbor. So, it is understandable that a layout is characterized by a vector $\mathbf{x}^{\mathrm{T}}=\left(\mathrm{x}_{1}, \ldots, \mathrm{x}_{21}\right)$, with components $\mathrm{x}_{\mathrm{k}}, \mathrm{k}=1, \ldots, 21$.

As mentioned above, water basins of yacht harbors are layed partly towards the land and partly towards the sea. In special occasions the water basin can be layed only on one of these directions. However, one of the projection matters of the harbor is defining how much the basin will lay on each of these directions. So, we assign: 
$\mathrm{x}_{22} \in \mathrm{R} \quad$ - the laying amount in the water basin

$\mathrm{x}_{23} \in \mathrm{R}$ - the laying amount in the land.

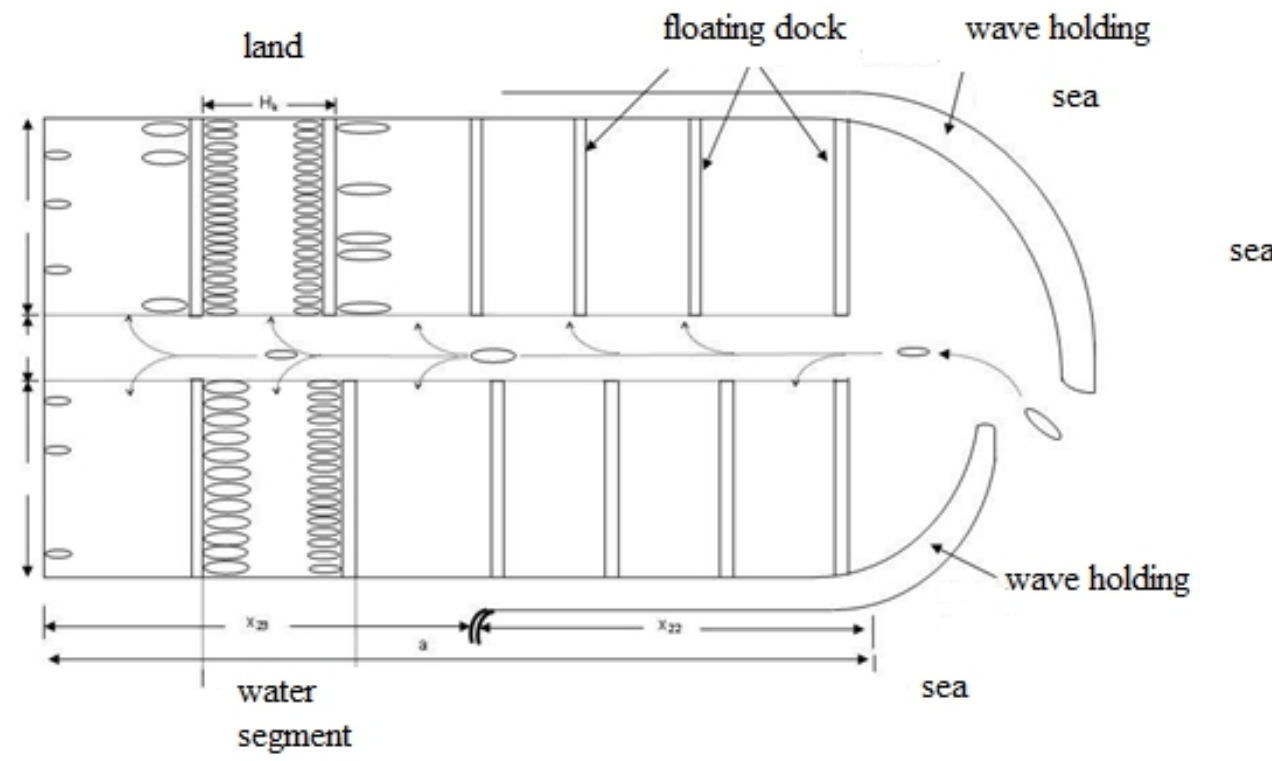

\section{Building the mathematical model}

It would be of high interest that the harbor plan contains as many boat locations for each lenght type, but their amount depends on the size of the water basin and the spectrum of the classes.

The sum $\sum_{1}^{21} H_{k} x_{k}$, shows the layout of the total length of all the water segments of the plan. In this case we assign $A_{6 \times 21}$ the matrix which is defined by the elements of table 1 .

\section{The capacity constraint.}

This condition expresses the physical limitation that the sum of all lengths $\mathrm{H}_{\mathrm{k}}$ of the water segments of a plan should not be bigger than the double of the longitudinal extension $\mathrm{a}=\mathrm{x} 22+\mathrm{x} 23$ of the water basin of the harbor (fig. 1). This condition is measured through this equation:

$$
\sum_{\mathrm{k}=1}^{21} \mathrm{H}_{\mathrm{k}} \mathrm{x}_{\mathrm{k}} \leq 2\left(\mathrm{x}_{22}+\mathrm{x}_{23}\right) \text {. }
$$

\section{The constraint of the boat classes}

The managerial experiences have shown that a yacht harbor which is built to serve one or two boat classes of small lengths, does not achieve the expected success from their activity. It is understandable that the presence of larger boats in a harbor proves a more qualified service, technical and 
administrative, and better accommodation conditions. So, indirectly, the presence of larger class boats is the best publicity for the quality of services that the harbor offers and at the same time leads to an increase in the number of boat location requests for all different classes. So, it is more reasonable to have a wider spectrum of boat classes.

It is known that the amount of boats in circulation decreases when the class's index increases. That is the reason that the managers of yacht harbors start predicting minimal limitations of the number of boat locations for the higher classes since the projection time. The minimal limitations can also be classified in special classes.

For a length class of $\mathrm{K}_{\mathrm{i}}, \mathrm{i}=1, \ldots, 6$, let's assign $\mathrm{g}_{\mathrm{i}}(\mathrm{x})$ to the number of boats which belong to the class of a certain plan $\mathrm{x}$. Considering what is mentioned above, the number is:

$$
\mathrm{g}_{\mathrm{i}}(\mathrm{x})=(\mathrm{A} \cdot \mathrm{x})_{\mathrm{i}}, \mathrm{i}=1, \ldots, 6
$$

If the minimal boundary set for this class is $\mathrm{N}_{\mathrm{i}}$, then the boundary is expressed by the inequation:

$$
\mathrm{g}_{\mathrm{i}}(\mathrm{x})=(\mathrm{A} \cdot \mathrm{x})_{\mathrm{i}} \geq \mathrm{N}_{\mathrm{i}}
$$

To make the idea proposal a bit more concrete, we suppose that the minimal boundaries belong to the group-class $\left(\mathrm{K}_{5}, \mathrm{~K}_{6}\right)$ and for the special classes $\mathrm{K}_{4}$ and $\mathrm{K}_{3}$. We assign these boundaries as $\mathrm{N}_{5,6}, \mathrm{~N}_{4}$ and $\mathrm{N}_{3}$ respectively. In the cases when the limitations are set for groups of classes the choice of a model can lead to the non-inclusion of one of the classes. But, it is important that the classes spectrum is complete. So, the final plan must guarantee the presence of the larger classes which we suppose is $\mathrm{K}_{\mathrm{s}}$. such a request is realized by adding the limitation that the sum of the $\mathrm{x}_{\mathrm{k}}$ values for $\mathrm{k}$ where $n_{s}(k) \neq 0$, must be $\geq 1$. For the group class $\left(\mathrm{K}_{5}, \mathrm{~K}_{6}\right)$ this step belongs concretely to class $\mathrm{K}_{6}$.

\section{Goals}

We assign $\mathrm{f}(\mathrm{x})$ to the sum of the total income from long term leasing of all the boat locations that the harbor plan contains. Keeping in mind the meaning of the matrix product A.x and the product of the vector $\mathrm{c}$ components, it is clear that the analytical expression of $f(x)$ is:

We assign:

$$
f(x)=c^{T}(A . x) \text {. }
$$

a 1 the distance from the coast, of the line where sea depth is $4.5 \mathrm{~m}$.

$\mathrm{a}_{2}$ the maximum boundary of the laying inside the ground of the water basin without natural, administrative or property obstacles.

With these symbols we can formulate the further objectives:

Ob.1. function $\mathrm{f}(\mathrm{x})$ should receive the highest value possible.

Ob.2. advancing at sea $\mathrm{X}_{22}$ should be as close to a1 as possible. 
Ob.3. inserting the water basin inside the ground $\mathrm{x}_{23}$ should not be bigger than a2.

\section{The mathematical model}

We assign $\mathrm{X}$ to the vector with components $\left(\mathrm{x}_{1}, \ldots, \mathrm{x}_{21}, \mathrm{x}_{22}, \mathrm{x}_{23}\right)$ where $x_{k} \in N, k=1, \ldots, 21$ and $x_{22}, x_{23} \in R$. So, the vector $X$ of the decision making variables is reached by adding the vector to the plan $\mathrm{x}$, the two new components $\mathrm{X}_{22}$ and $\mathrm{x}_{23}$ in real values which represent the mass of advancement of the water basin in the sea and its infiltration into the water. We assign $c_{1}(X)=f(x), c_{2}(X), c_{3}(X)$ respectively the functions that represent objectives 1,2,3 depending on the decision making variables. It is clear that $c_{2}(X)=X_{22}, c_{3}(X)=X_{23}$, while $c_{1}(X)$ is expressed as shown below by using the data from table 1 . The objectives 2 and 3 are expressed respectively by the equation: $c_{2}(X)=x_{22}=a_{1}$ and inequation $c_{3}(X)=x_{23} \leq a_{2}$.

And now, the problem of rationally using the water basin of a yacht harbor takes this mathematical form:

Ob.1. Maximizing the function of the income (6) which when developed is:

$$
\begin{aligned}
\mathrm{c}_{1}(X)=2 \mathrm{n}_{1} \mathrm{c}_{1} \mathrm{X}_{1}+\left(\mathrm{n}_{1} \mathrm{c}_{1}+\mathrm{n}_{2} \mathrm{c}_{2}\right) \mathrm{X}_{2}+\left(\mathrm{n}_{1} \mathrm{c}_{1}+\mathrm{n}_{3} \mathrm{c}_{3}\right) \mathrm{X}_{3}+\left(\mathrm{n}_{1} \mathrm{c}_{1}+\mathrm{n}_{4} \mathrm{c}_{4}\right) \mathrm{X}_{4}+\left(\mathrm{n}_{1} \mathrm{c}_{1}+\mathrm{n}_{5} \mathrm{c}_{5}\right) \mathrm{X}_{5}+ \\
+\left(\mathrm{n}_{1} \mathrm{c}_{1}+\mathrm{n}_{6} \mathrm{c}_{6}\right) \mathrm{X}_{6}+2 \mathrm{n}_{2} \mathrm{c}_{2} \mathrm{X}_{7}+\left(\mathrm{n}_{2} \mathrm{c}_{2}+\mathrm{n}_{3} \mathrm{c}_{3}\right) \mathrm{X}_{8}+\left(\mathrm{n}_{2} \mathrm{c}_{2}+\mathrm{n}_{4} \mathrm{c}_{4}\right) \mathrm{X}_{9}+\left(\mathrm{n}_{2} \mathrm{c}_{2}+\mathrm{n}_{5} \mathrm{c}_{5}\right) \mathrm{X}_{10}+ \\
+\left(\mathrm{n}_{2} \mathrm{c}_{2}+\mathrm{n}_{6} \mathrm{c}_{6}\right) \mathrm{X}_{11}+2 \mathrm{n}_{3} \mathrm{c}_{3} \mathrm{X}_{12}++\left(\mathrm{n}_{3} \mathrm{c}_{3}+\mathrm{n}_{4} \mathrm{c}_{4}\right) \mathrm{X}_{13}+\left(\mathrm{n}_{3} \mathrm{c}_{3}+\mathrm{n}_{5} \mathrm{c}_{5}\right) \mathrm{X}_{14}+ \\
+\left(\mathrm{n}_{3} \mathrm{c}_{3}+\mathrm{n}_{6} \mathrm{c}_{6}\right) \mathrm{X}_{15}+2 \mathrm{n}_{4} \mathrm{c}_{4} \mathrm{X}_{16}+\left(\mathrm{n}_{4} \mathrm{c}_{4}+\mathrm{n}_{5} \mathrm{c}_{5}\right) \mathrm{X}_{17}+\left(\mathrm{n}_{4} \mathrm{c}_{4}+\mathrm{n}_{6} \mathrm{c}_{6}\right) \mathrm{X}_{18}+ \\
\quad+2 \mathrm{n}_{5} \mathrm{c}_{5} \mathrm{X}_{19}+\left(\mathrm{n}_{5} \mathrm{c}_{5}+\mathrm{n}_{6} \mathrm{c}_{6}\right) \mathrm{X}_{20}+2 \mathrm{n}_{6} \mathrm{c}_{6} \mathrm{X}_{21}
\end{aligned}
$$

Ob.2. Achieving this equation:

$\mathrm{X}_{22}=\mathrm{a}_{1}$

Ob.3. Achieving this inequation:

$\mathrm{x}_{23} \leq \mathrm{a} 2$.

With the condition that all of the above conditions are made true through these inequations:

$$
\begin{gathered}
\sum_{\mathrm{k}=1}^{21} \mathrm{H}_{\mathrm{k}} \mathrm{x}_{\mathrm{k}} \leq 2\left(\mathrm{x}_{22}+\mathrm{x}_{23}\right) \\
\mathrm{n}_{5} \mathrm{x}_{5}+\mathrm{n}_{6} \mathrm{x}_{6}+\mathrm{n}_{5} \mathrm{x}_{10}+\mathrm{n}_{6} \mathrm{x}_{11}+\mathrm{n}_{5} \mathrm{x}_{14}+\mathrm{n}_{6} \mathrm{x}_{15}+\mathrm{n}_{5} \mathrm{x}_{17} \\
+\mathrm{n}_{6} \mathrm{x}_{18}+2 \mathrm{n}_{5} \mathrm{x}_{19}+\left(\mathrm{n}_{5}+\mathrm{n}_{6}\right) \mathrm{x}_{20}+2 \mathrm{n}_{6} \mathrm{x}_{21} \geq \mathrm{N}_{5,6} \\
\mathrm{x}_{6}+\mathrm{x}_{11}+\mathrm{x}_{15}+\mathrm{x}_{18}+\mathrm{x}_{20}+\mathrm{x}_{21} \geq 1 \\
\mathrm{n}_{4} \mathrm{x}_{4}+\mathrm{n}_{4} \mathrm{x}_{9}+\mathrm{n}_{4} \mathrm{x}_{13}+2 \mathrm{n}_{4} \mathrm{x}_{16}+\mathrm{n}_{4} \mathrm{x}_{17}+\mathrm{n}_{4} \mathrm{x}_{18} \geq \mathrm{N}_{4} \\
\mathrm{n}_{3} \mathrm{x}_{3}+\mathrm{n}_{3} \mathrm{x}_{8}+2 \mathrm{n}_{3} \mathrm{x}_{12}+\mathrm{n}_{3} \mathrm{x}_{13}+\mathrm{n}_{3} \mathrm{x}_{14}+\mathrm{n}_{3} \mathrm{x}_{15} \geq \mathrm{N}_{3} \\
\mathrm{x}_{\mathrm{k}} \in \mathrm{N} \cup\{0\}, \quad \mathrm{k}=1, \ldots, 21 \\
\mathrm{x}_{22} \geq 0, \mathrm{x}_{23} \geq 0
\end{gathered}
$$


This mathematical model is goal programming. The solutions of the problems for goal programming are found by returning them into mathematical problems (for example [3],[4],[5] etc). In our case, just as the functions $c_{1}(X), c_{2}(X), c_{3}(X)$ express the objectives of the problem, the inequations of the boundary system (7), are all linear. This means that the mathematical program also will be a linear programming.

In order for the goal programming to turn into a linear programming it is necessary that the objectives, which in the problem setting do not have any numerical target, are defined in the most argumented way possible. In the case of our problem, related to the first objectives which concerns the expected income from all the boat locations, there is no expressed numerical target. In this case those who study the project and calculate the cost of actualizing the harbor and the expected income ratio, also define a satisfactory amount which makes the project feasible. We assign this satisfactory amount with the symbol F. The depths $\mathrm{a}_{1}$ and $\mathrm{a}_{2}$ of the harbor insertion into the sea and land are the targets for the other two objective functions $\mathrm{c}_{2}(\mathrm{X})$ and $\mathrm{c}_{3}(\mathrm{X})$.

We assign:

$$
\mathrm{y}_{1}^{-}, \mathrm{y}_{1}^{+} ; \mathrm{y}_{2}^{-}, \mathrm{y}_{2}^{+} ; \mathrm{y}_{3}^{-}, \mathrm{y}_{3}^{+} \in \mathrm{R}^{+}
$$

the variables of the function values deviations $\mathrm{c}_{1}(\mathrm{X}), \mathrm{c}_{2}(\mathrm{X}), \mathrm{c}_{3}(\mathrm{X})$ by the respective targets for each allowable solution $X$ of the system (7).

With the insertion of the deviation variables it is possible to turn the problem into a linear programming through the two transformational operations:

(1) Construction of a summarizing objective function

(2) Insertion in the limitations system of a new equation for each objective.

For the problem in our case these operations are set out as below:

(1) According to the weights method, as a summarizing objective function we use a linear function of the deviation variables, whose coefficients are defined based on the importance of each deviation. In this actual case we can consider as an important amount not passing the maximum limitation of how much we lay into the ground and water ( $\left.\mathrm{a}_{2}\right)$ and we give a weight $\omega_{3}^{+}=5$ to the variable of surpassing this limitation $\mathrm{y}_{3}^{+}$, while to the variable of non achieving this limitation $y_{3}^{-}$we can give the weight $\omega_{3}^{-}=0$ since not achieving that limitation is not important.

For a sandy coastline, as it is the biggest portion of our coast line, we can initially take as a value a1 the distance from the depth of $4.5 \mathrm{~m}$. Probably, this distance gives the harbor adequate dimensions. Not achieving a does not cause an issue for the selected objectives. That is why we assign the weight 
$\omega_{2}^{-}=0$ to the variable $\mathrm{y}_{2}^{-}$which shows how much the a1 distance is not reached. Meanwhile, exceeding that distance a1 is important because the expenses of building the wave holding become much higher compared to the scenario where the distance is not exceeded. For this reason the variable $\mathrm{y}_{2}^{+}$ receives a positive weight (see below).

Finally, for the first objective of maximizing income, exceeding target $\mathrm{F}$ is not problematic. For this reason the variable $\mathrm{y}_{1}^{+}$is assigned a weight of $\omega_{1}^{+}=0$. It is also crucial that this target is achieved. Based on the actual circumstances we can compare the increase in expenses when target a1 is exceeded to the decrease in income that not achieving this target brings. Based on such a comparison are compared the weights assigned to variables $\mathrm{y}_{1}^{-}$and $\omega_{2}^{+}=2$.

We assign $\tilde{\mathbf{X}}$ to the vector of all variables (a total of 29) which we get by adding the six deviation variables $y_{1}^{-}, y_{1}^{+}, y_{2}^{-}, y_{2}^{+}, y_{3}^{-}, \mathrm{y}_{3}^{+}$to the vector $X$. After evaluating the weights of the deviation variables, the summarized objective function which is closest to expressing the objective function target is:

$$
\Phi(\tilde{\mathbf{X}})=\omega_{1}^{-} \mathrm{y}_{1}^{-}+\omega_{2}^{+} \mathrm{y}_{2}^{+}+\omega_{3}^{+} \mathrm{y}_{3}^{+}=3 \mathrm{y}_{1}^{-}+2 \mathrm{y}_{2}^{+}+5 \mathrm{y}_{3}^{+}
$$

(2) The requests for achieving the accepted targets related to the objective functions $c_{1}(X), c_{2}(X), c_{3}(X$, after inserting the deviation variables, are mathematically expressed through these equations:

$$
\begin{array}{rrr}
\mathrm{c}_{1}(\mathrm{X})+\mathrm{y}_{1}^{-}-\mathrm{y}_{1}^{+} & =\mathrm{F} \\
\mathrm{x}_{22} & +\mathrm{y}_{2}^{-}-\mathrm{y}_{2}^{+} & =\mathrm{a}_{1} \\
\mathrm{x}_{23} & +\mathrm{y}_{3}^{-}-\mathrm{y}_{3}^{+} & =\mathrm{a}_{2}
\end{array}
$$

Finally, by adding the limitations (7) to the three last equations, the problem of optimal use of the water basin of a yacht harbor turns from an objective function program to a linear program with mixed variables:

$$
\text { Min: } \Phi(\tilde{\mathbf{X}})=\omega_{1}^{-} \mathrm{y}_{1}^{-}+\omega_{2}^{+} \mathrm{y}_{2}^{+}+\omega_{3}^{+} \mathrm{y}_{3}^{+}=3 \mathrm{y}_{1}^{-}+2 \mathrm{y}_{2}^{+}+5 \mathrm{y}_{3}^{+}
$$

With the constraints that the system of limitations below is verified: 


$$
\begin{aligned}
& \left\{\begin{array}{c}
2 \mathrm{n}_{1} \mathrm{c}_{1} \mathrm{x}_{1}+\left(\mathrm{n}_{1} \mathrm{c}_{1}+\mathrm{n}_{2} \mathrm{c}_{2}\right) \mathrm{x}_{2}+\left(\mathrm{n}_{1} \mathrm{c}_{1}+\mathrm{n}_{3} \mathrm{c}_{3}\right) \mathrm{x}_{3}+\left(\mathrm{n}_{1} \mathrm{c}_{1}+\mathrm{n}_{4} \mathrm{c}_{4}\right) \mathrm{x}_{4}+ \\
+\left(\mathrm{n}_{1} \mathrm{c}_{1}+\mathrm{n}_{5} \mathrm{c}_{5}\right) \mathrm{x}_{5}+\left(\mathrm{n}_{1} \mathrm{c}_{1}+\mathrm{n}_{6} \mathrm{c}_{6}\right) \mathrm{x}_{6}+2 \mathrm{n}_{2} \mathrm{c}_{2} \mathrm{x}_{7}+\left(\mathrm{n}_{2} \mathrm{c}_{2}+\mathrm{n}_{3} \mathrm{c}_{3}\right) \mathrm{x}_{8}+ \\
+\left(\mathrm{n}_{2} \mathrm{c}_{2}+\mathrm{n}_{4} \mathrm{c}_{4}\right) \mathrm{x}_{9}+\left(\mathrm{n}_{2} \mathrm{c}_{2}+\mathrm{n}_{5} \mathrm{c}_{5}\right) \mathrm{x}_{10}+\left(\mathrm{n}_{2} \mathrm{c}_{2}+\mathrm{n}_{6} \mathrm{c}_{6}\right) \mathrm{x}_{11}+2 \mathrm{n}_{3} \mathrm{c}_{3} \mathrm{x}_{12}+ \\
+\left(\mathrm{n}_{3} \mathrm{c}_{3}+\mathrm{n}_{4} \mathrm{c}_{4}\right) \mathrm{x}_{13}+\left(\mathrm{n}_{3} \mathrm{c}_{3}+\mathrm{n}_{5} \mathrm{c}_{5}\right) \mathrm{x}_{1 \times 4}+\left(\mathrm{n}_{3} \mathrm{c}_{3}+\mathrm{n}_{6} \mathrm{c}_{6}\right) \mathrm{x}_{15}+2 \mathrm{n}_{4} \mathrm{c}_{4} \mathrm{x}_{16}+ \\
+\left(\mathrm{n}_{4} \mathrm{c}_{4}+\mathrm{n}_{5} \mathrm{c}_{5}\right) \mathrm{x}_{17}+\left(\mathrm{n}_{4} \mathrm{c}_{4}+\mathrm{n}_{6} \mathrm{c}_{6}\right) \mathrm{x}_{18}+2 \mathrm{n}_{5} \mathrm{c}_{5} \mathrm{x}_{19}+\left(\mathrm{n}_{5} \mathrm{c}_{5}+\mathrm{n}_{6} \mathrm{c}_{6}\right) \mathrm{x}_{20}+ \\
2 \mathrm{n}_{6} \mathrm{c}_{6} \mathrm{x}_{21}+\mathrm{y}_{1}^{-}-\mathrm{y}_{1}^{+} \\
\mathrm{x}_{22}=\mathcal{F}= \\
\mathrm{x}_{23} \\
+\mathrm{y}_{2}^{-}-\mathrm{y}_{2}^{+} \quad=\mathrm{a}_{1} \\
+\mathrm{y}_{3}^{-}-\mathrm{y}_{3}^{+}=\mathrm{a}_{2}
\end{array}\right. \\
& \sum_{\mathrm{k}=1}^{21} \mathrm{H}_{\mathrm{k}} \mathrm{x}_{\mathrm{k}} \leq 2\left(\mathrm{x}_{22}+\mathrm{x}_{23}\right) \\
& \mathrm{n}_{5} \mathrm{x}_{5}+\mathrm{n}_{6} \mathrm{x}_{6}+\mathrm{n}_{5} \mathrm{x}_{10}+\mathrm{n}_{6} \mathrm{x}_{11}+\mathrm{n}_{5} \mathrm{x}_{14}+\mathrm{n}_{6} \mathrm{x}_{15}+\mathrm{n}_{5} \mathrm{x}_{17}+\mathrm{n}_{6} \mathrm{x}_{18}+ \\
& +2 \mathrm{n}_{5} \mathrm{x}_{19}+\left(\mathrm{n}_{5}+\mathrm{n}_{6}\right) \mathrm{x}_{20}+2 \mathrm{n}_{6} \mathrm{x}_{21} \geq \mathrm{N}_{5,6} \\
& \mathrm{x}_{6}+\mathrm{x}_{11}+\mathrm{x}_{15}+\mathrm{x}_{18}+\mathrm{x}_{20}+\mathrm{x}_{21} \geq 1 \\
& \mathrm{n}_{4}\left(\mathrm{x}_{4}+\mathrm{x}_{9}+\mathrm{x}_{13}+2 \mathrm{x}_{16}+\mathrm{x}_{17}+\mathrm{x}_{18}\right) \geq \mathrm{N}_{4} \\
& \mathrm{n}_{3}\left(\mathrm{x}_{3}+\mathrm{x}_{8}+2 \mathrm{x}_{12}+\mathrm{x}_{13}+\mathrm{x}_{14}+\mathrm{x}_{15}\right) \geq \mathrm{N}_{3} \\
& \mathrm{x}_{\mathrm{k}} \in \mathrm{N} \cup\{0\}, \mathrm{k}=1, \ldots, 21 \text {; } \\
& \mathrm{x}_{22}, \mathrm{x}_{23}, \mathrm{y}_{1}^{-}, \mathrm{y}_{1}^{+}, \mathrm{y}_{2}^{-}, \mathrm{y}_{2}^{+}, \mathrm{y}_{3}^{-}, \mathrm{y}_{3}^{+} \geq 0
\end{aligned}
$$

The linear programing with mixed variables has relatively small proportions. Different programs and methods are used to solve such a problem (Hillier 2005). When the solution is not acceptable based on one or more selected targets, then without changing the model above we can analyse and re-define some targets or goals so that the problem has a solution. This practice can be repeated until we achieve the desired results.

For different reasons (nature, administrative limitations, property rights, etc), it can become difficult for the water basin to lay into the ground and pass a. This means that the Objective 3 has been reached. Now we have a situation where the set of objectives are highly different based on their importance. In such cases, a hierarchy of priorities is defined. In the first priority are included the highly important objectives, whose reach can not be compromised because of the optimism for the other objectives. With such a criteria, in the set of the remaining objectives after removing those of first priority, are defined the second priority objectives and so on. This method of treating objectives based on priorities is called preemtive method in goal programming (Taha, 2007). 


\begin{tabular}{|c|c|c|c|c|c|c|c|c|c|c|c|c|c|c|c|c|c|c|c|c|c|c|}
\hline KLas & $\begin{array}{r}\mathrm{T}_{1} \\
(1,1)\end{array}$ & $\begin{array}{c}\mathrm{T}_{2} \\
(1,2)\end{array}$ & $\begin{array}{c}\mathrm{T}_{3} \\
(1,3\end{array}$ & $\begin{array}{c}\mathrm{T}_{4} \\
(1,4)\end{array}$ & $\begin{array}{c}\mathrm{T}_{5} \\
(1,5)\end{array}$ & $\begin{array}{l}\mathrm{T}_{6} \\
(1,6)\end{array}$ & $\left\{\begin{array}{c}\mathrm{T}_{7} \\
(2,2)\end{array}\right.$ & $\begin{array}{c}\mathrm{T}_{8} \\
(2,3\end{array}$ & $\begin{array}{c}\mathrm{T}_{9} \\
(2,4)\end{array}$ & $\begin{array}{l}\mathrm{T}_{100} \\
(2,5\end{array}$ & $\begin{array}{l}\mathrm{T}_{1,1} \\
(2,6)\end{array}$ & $\left\{\begin{array}{l}\mathrm{T}_{12} \\
(3,3)\end{array}\right.$ & $\begin{array}{l}\mathrm{T}_{13} \\
(3,4)\end{array}$ & $\begin{array}{l}T_{14} \\
(3,5)\end{array}$ & $\begin{array}{l}\mathrm{T}_{15} \\
(3,6)\end{array}$ & $\begin{array}{l}\mathrm{T}_{16} \\
(4,4)\end{array}$ & $\left\{\begin{array}{c}\mathrm{T}_{17} \\
(4,5)\end{array}\right.$ & $\begin{array}{l}T_{18} \\
(4,6)\end{array}$ & $\begin{array}{l}\mathrm{T}_{19} \\
(5,5)\end{array}$ & $\left\{\begin{array}{l}\mathrm{T}_{20} \\
(5,6)\end{array}\right.$ & $\begin{array}{l}T_{21} \\
(6,6)\end{array}$ & C \\
\hline $\mathrm{K}_{1}$ & $2 n_{1}$ & $\mathrm{n}_{1}$ & $\mathrm{n}_{\mathrm{m}}$ & $\mathrm{n}_{\lambda}$ & $\mathrm{n}_{1}$ & $\mathrm{n}_{\mathrm{\mu}}$ & 0 & 0 & 0 & 0 & 0 & 0 & 0 & 0 & 0 & 0 & 0 & 0 & 0 & 0 & 0 & $\mathrm{c}_{1}$ \\
\hline $\mathrm{K}_{2}$ & 0 & $\mathrm{n}_{2}$ & 0 & 0 & 0 & 0 & $2 n_{2}$ & $\mathrm{n}_{2}$ & $\mathrm{n}_{2}$ & $\mathrm{n}_{2}$ & $\mathrm{n}_{2}$ & 0 & 0 & 0 & 0 & 0 & 0 & 0 & 0 & 0 & 0 & $c_{2}$ \\
\hline $\mathrm{K}_{3}$ & 0 & 0 & $\mathrm{n}_{3}$ & 0 & 0 & 0 & 0 & $\mathrm{n}_{3}$ & 0 & 0 & 0 & $2 n_{3}$ & $\mathrm{n}_{3}$ & $n_{3}$ & $\mathrm{n}_{3}$ & 0 & 0 & 0 & 0 & 0 & 0 & $c_{3}$ \\
\hline $\mathrm{K}_{4}$ & 0 & 0 & 0 & $\mathrm{n}_{4}$ & 0 & 0 & 0 & 0 & $\mathrm{n}_{4}$ & 0 & 0 & 0 & $\mathrm{n}_{4}$ & 0 & 0 & $2 n_{4}$ & $\mathrm{n}_{4}$ & $\mathrm{n}_{4}$ & 0 & 0 & 0 & $c_{4}$ \\
\hline $\mathrm{K}_{5}$ & 0 & 0 & 0 & 0 & $\mathrm{n}_{5}$ & 0 & 0 & 0 & 0 & $\mathrm{n}_{5}$ & 0 & 0 & 0 & $\mathrm{n}_{5}$ & 0 & 0 & $\mathrm{n}_{5}$ & 0 & $2 n_{5}$ & $\mathrm{n}_{5}$ & 0 & $c_{5}$ \\
\hline $\mathrm{K}_{5}$ & 0 & 0 & 0 & 0 & 0 & $\mathrm{n}_{6}$ & 0 & 0 & 0 & 0 & $\mathrm{n}_{6}$ & 0 & 0 & 0 & $\mathrm{n}_{6}$ & 0 & 0 & $\mathrm{n}_{6}$ & 0 & $\mathrm{n}_{6}$ & $2 \mathrm{n}_{6}$ & $c_{6}$ \\
\hline
\end{tabular}

\begin{tabular}{|l|lllllllllllllllllllll}
$\mathrm{x}$ & $\mathrm{x}_{1}$ & $\mathrm{x}_{2}$ & $\mathrm{x}_{3}$ & $\mathrm{x}_{4}$ & $\mathrm{x}_{5}$ & $\mathrm{x}_{6}$ & $\mathrm{x}_{7}$ & $\mathrm{x}_{8}$ & $\mathrm{x}_{9}$ & $\mathrm{x}_{10}$ & $\mathrm{x}_{11}$ & $\mathrm{x}_{12}$ & $\mathrm{x}_{13}$ & $\mathrm{x}_{14}$ & $\mathrm{x}_{15}$ & $\mathrm{x}_{16}$ & $\mathrm{x}_{17}$ & $\mathrm{x}_{18}$ & $\mathrm{x}_{19}$ & $\mathrm{x}_{20}$ & $\mathrm{x}_{21}$ \\
\hline
\end{tabular}

\section{Conclusion}

In the phase of the fisibility study of different project ideas, using mathematical models brings valuable help to increasing the accuracy of the study conclusions. As shown in this article, the mathematical models of goal programming, are very suitable for such studies as they, in their own nature, in one model include different evaluation chriteria of the project fisibility.

\section{References:}

Billionnet A. Optimisation Discrète, Dunod, Paris 2007

Colorni A. Ricerca Operativa, clup, Milano, 1984

Hillier S. F., Lieberman J. G. Operations Research, eight ed. McGray Hill, 2005

Katta G., Murty, Operations Research, Deterministic Optimization Model, (C) Prentice-Hall.

Nesa Wu, Richard Coppins, Linear Programming and extensions, New York, McGraw-Hill, 1981

Taha A. H. Operation Research, an introduction, Pearson Education, (C) Inc. 2007. 